\title{
SOLID DOSAGE FORM: TABLET /GRANULATION METHOD / DIFFERENT TYPES OF TABLET DEFECTS
}

\author{
Dinesh Kaushik $^{1}$
}

Abstract:-Tablet is a solid dosage form which is administrated orally. This is found in powder, crystalline or granule from. Precisly compressed from of powder is called Tablet. Tablets are manufactured by compression of active ingredients with or without diluents. Tablets are manufactured by various techniques such as dry granulation, wet granulation or direct compression method.Oral route is most convenient and safe route of administration of drugs (Tablet). The tablets are found in various shapes such as round,oval,\& triangular Shape.The upper and lower surface of tablet may be flat or convex shape.

Various Types of Tablets:-
(A) Film coated Tablet
(B) Sugar coated Tablet
(C) Chewable Tablet
(D) Enteric coated Tablet
(E) Delay relcased Tablet
(F) Sublingual Tablet
(G) Multiple compressed Tablet
(H) Effervescent Tablet
(I) Vaginal Tablet or Implantation Tablet

(A) Film coated Tablet: This type of compressed tablet covered with a thin Polymer of layer which is water solvent.

(B) Sugar coated Tablet : These are compressed Tablet coated with sugar to reduce the bitter taste or odour of drug.

\footnotetext{
${ }^{1}$ Approved Manufacturing Chemist ( Tablet \& Capsule Section) State Drug Controller, Haryana
} 
(C) Enteric coated Tablet : These are compressed tablet which are covered with enteric coating material which are dissolved in intestine covered by cellulose acetate phthalate. These type of tablet is expensive.

(D) Multiple compressed Tablet : These type of tablets are compressed more than one time.

(E) Chewable Tablet : These types of tablet are chewed in between the teeth before ingestion. Antacid and vitamins tablet are chewable tablets.

(F) Delay Released tablet : These type of Tablet is either uncoated or coated. This type of Tablets or drugs released into gastro intestinal tract. Its prolong the effect of drug and reduced the frequency of administration of Drugs. Such as indomethacin.

(G) Sublingual Tablet : These types of tablet is to be placed below the tongue for slow release of drugs. Dissolve in 1 or 2 minutes. Nitroglycerin or disprin is prepared in this formulation.

(H) Effervescent Tablet : They contain sodium bio-carbonate and citric acid with the drug during addition in water they release $\mathrm{CO} 2$ and produce the effervescene.

(I) Vaginal Tablet or Implantation Tablet : These types of tablets are administered by other routes.

Excipients used for Tablet Formulation:- Tablets are prepared by compression technique which includes various diluents, binders, disintegrant, lubricants, glidant,colouring agent, sweeting agent \& Flavouring Agent.

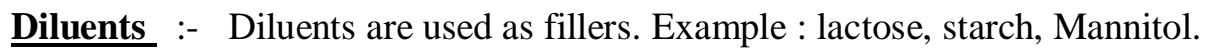

Binders :-Binders are used as binding agent in the tablet formulation Example: CMC, acacia.

Disintegrant :- These are added to disintegrate the tablet into particles.

Example : Starch, cellulose.

Lubricant: - Lubricants are used to prevent the sticking of powder to dies and punches. Example : Talc, stearic, magnesium sterate.

Glidants :- Reduce the friction. Example : Starch, talc.

Colouring Agent :- Help in elegant appearance of tablet. Example: Brilliant blue

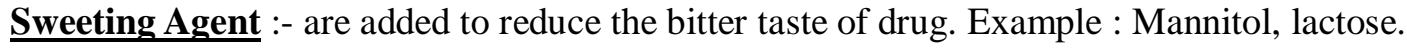

Flavouring Agent :-Added to impart the flavours or odors in the formulation. Example: Methanol.

\section{$\underline{\text { Granulation }}$}

Granulation is a process to produce the solid dosage forms of drugs. It is often used to convert powdered drug formulations into physical form that has improved flow and compaction characteristic to produce Tablet with uniform contents and consistent hardness and other properties. Different Types of Granulation Methods carried out are being described as under.

\section{Dry granulation method}

\section{Wet granulation}




\section{Direct compression (Slugging)}

\section{Dry Granulation Method}

Dry powder to be blend can not be directly compressed because of poor flow of properties. This is done on the basis of tablet press for slugging. Slugging technique are used to form the granules. The active ingredients, diluents, excipent are blended together to form the slug. The compressed slug is passed through the mesh or through milling and other remaining lubricants are added to the granulation to ensure that it blended properly to compress the powder to form the tablet. This is also called double compression method.

\section{Wet granulation method}

This method involves various steps which are described below here:

Dry Mixing All the ingredients

Add $\downarrow$ Starch Paste $(40 \circ \mathrm{C})$

Wet Granulation

$\downarrow$

Milling

$\downarrow$

Drying

$\downarrow$

Sieving

$\downarrow$

Blending

$\downarrow$

Compression of tablets

Excipients used in Wet Granulation

\begin{tabular}{|l|l|l|}
\hline Function & Excipient & Level \\
\hline Diluent & M.C.C. & $10-30 \%$ \\
& DCP & Upto 90\% \\
& Mannitol & Upto 90\% \\
\hline Binder & Povidone & $1 \%-3 \%$ \\
& Hydroxy propylcellulose & $1 \%-3 \%$ \\
& Pre gelatinised & \\
& Starch & $2 \%-5 \%$ \\
\hline Dissintegrant & S.S.G. & $2 \%-6 \%$ \\
\hline
\end{tabular}




\begin{tabular}{|l|l|l|}
\hline & CCS & $2 \%-6 \%$ \\
& CrossPovidone & $2 \%-6 \%$ \\
\hline Lubircant & $\begin{array}{l}\text { Mag. Sterate } \\
\text { Tal/stearic acid }\end{array}$ & $\begin{array}{l}0.5 \% \text { to } 1 \% \\
3 \% \text { to } 5 \% / 1 \% \text { to } 2 \%\end{array}$ \\
\hline Glidant & Colloidal Silicon dioxide & $0.1 \%$ to $0.3 \%$ \\
\hline
\end{tabular}

\section{Direct Compression Method}

This method involves the direct compression of powder into tablet. Direct compression method is a popular choice because this is shortest and most effective method to produce tablets. The manufacturer can blend the API with the Excipient and lubricant followed by compression. No additional process steps are required.

\section{Tablet defects during compression :}

1. Capping

2. Lamination

3. Cracking

4. Chipping

5. Sticking

6. $\quad$ Picking

7. Mottling

Capping : It is partial or complete separation of top or bottom of tablet due to air entrapment in granulation.

\section{Reasons:}

(A) Large amount of fine granulation

(B) Excess Dry or low moisture content

(C) Insufficient lubricant

(D) Insufficient amount of binder

Lamination : Separation of Tablet in two or more layer due to air entrapment in granulation.

Reasons:

1. Oily or waxy material in granules

2. Excess of hydrophobic lubricant

3. Magnesium sterate

Chipping : Chiping is defined as breakaing of tablet edges.

Reason
(A) Sticking on punch faces
(B) Too dry granules
(C) Too much binding causes Chipping at bottom 


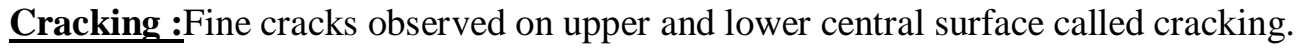

\section{$\underline{\text { Reason }}$}

1. Large size of granules

2. Too dry granules

3. Tablet expand

Sticking : Arise due to excess moisture in the granules.

Reason:

1. Granules not dry properly

2. Too much binders

3 Improper lubrication

4. Too soft or weak granules

Picking - The tablet surface removed by punch during compression.

Reason

1. Excess moisture in granules

2. Improper lubrication

3. Too much amount of binder

Mottling --- Unequal distribution of colour during coating.

Reason---- coloured drug used along with colourless or white coloured excepients.

\section{$\underline{\text { Evaluation Test }}$}

After the tablet compression various evaluation test are carried out withstand sufficient mechanical strength.

1. Wet variation test

2. Hardness Test

3. Friability test

4. Disintegration test

5. Dissolution test

A. Weight variation Test

20 Tablets are weighed finally avg. weight of tablet is determined. As per Indian Pharmacopeia specification of tablet weight is as follows :-

$<50 \mathrm{mg}$. deviation upto $10 \%$ allowed

$80-250 \mathrm{Mg}$. -Deviation up to $7.5 \%$ allowed

$250 \mathrm{Mg}$. -Deviation up to $5 \%$ allowed

\section{B. Hardness test}


This test is performed to ensure that the tablet withstand mechanical stock during the transportation or packaging of tablet. Mosanto hardness tester is used. The tablet hardness should be $2.5 \mathrm{Kg}$. to 5 $\mathrm{Kg} . / \mathrm{Cm} 2$. for extended released tablet hardness should be $5 \mathrm{~kg}-7.5 \mathrm{Kg} / \mathrm{Cm} 2$

\section{Friability Test}

This test is performed to ensure the mechanical strength of tablet during transportation or shipping and packaging in friability test appratus.

Formula: $\quad$ Initial weight - less weight $\times 100$

$$
\text { Initial weight }
$$

\section{Disintegration Test}

Disintegration is break down of tablet into finally divided particulates or granules in GI tract. Disintegration time for uncoated tablets is 15 Min while film coated 30 Min and 60 Min for sugar coated tablets

\section{E. Dissolution Test}

The time required for the given $\%$ of drug in tablet in to solution under specified set of conditions as in vitro Test.

\section{REFERENCES}

[1]. Remington J. Remington: The Science and Practise of Pharmacy; Nineteenth Edition: volume// $1615-1641$.

[2]. Lachman L. Lieberman,H.A. Joseph L.K.The Theory and Practise of Industrial Pharmacy, Varghese Publishing House, Mumbai; Third Edition PP 297-321.

[3]. Lachman L. Liberman H; and Kanig J. The Theory and practise of Industrial Pharmacy; third Edition; 293-345, 346-373.

[4]. Picta R. Problems Associated with Tablet Manufacturing, 2011. 